\title{
Efficacy of Natamycin Against Gray Mold of Stored Mandarin Fruit Caused by Isolates of Botrytis cinerea With Multiple Fungicide Resistance
}

\author{
S. Saito, F. Wang, and C. L. Xiao ${ }^{\dagger}$ \\ U.S. Department of Agriculture-Agricultural Research Service (USDA-ARS), San Joaquin Valley Agricultural Sciences Center, \\ Parlier, CA 93648
}

\begin{abstract}
Gray mold caused by Botrytis cinerea is an emerging postharvest disease of mandarin fruit in California. Management of postharvest diseases of mandarins relies on postharvest fungicides; however, multiple resistance to fungicides of different modes of action is common in $B$. cinerea populations from mandarin, leading to their failure to control decay. Natamycin is commonly used in the food industry as an additive, and it has been registered as a biofungicide for postharvest use on citrus and some other fruits. Sensitivity to natamycin of 64 isolates of $B$. cinerea from decayed mandarin fruit with known resistance phenotypes to other citrus postharvest fungicides (azoxystrobin, fludioxonil, pyrimethanil, and thiabendazole) was tested. Effective concentrations of natamycin to cause a $50 \%$ reduction relative to the

(mean of $1.578 \mu \mathrm{g} / \mathrm{ml}$ ). Minimum inhibitory concentrations where no fungal growth was present were 0.7 to $1.0 \mu \mathrm{g} / \mathrm{ml}$ for conidial germination and 5.0 to $10.0 \mu \mathrm{g} / \mathrm{ml}$ for mycelial growth. No cross-resistance between natamycin and other citrus postharvest fungicides was detected. Decay control efficacy tests with natamycin were conducted on mandarin fruit inoculated with $B$. cinerea isolates exhibiting five different fungicide resistance phenotypes, and natamycin significantly reduced incidence and lesion size of gray mold on fruit, regardless of fungicide resistance phenotypes. Natamycin has the potential to be an effective tool for integration into postharvest fungicide programs to control gray mold and manage $B$. cinerea isolates resistant to fungicides with other modes of action.
\end{abstract} control for conidial germination were from 0.324 to $0.567 \mu \mathrm{g} / \mathrm{ml}$ (mean of $0.444 \mu \mathrm{g} / \mathrm{ml}$ ), and those for mycelial growth were 1.021 to $2.007 \mu \mathrm{g} / \mathrm{ml}$
Keywords: chemical, disease management, fruit, fungi, tree fruits
Mandarin fruit (Citrus reticulata) has become an increasingly important part of California's citrus industry (Webber et al. 2014). The total acreage of mandarins in California has tripled over the last 15 years, with a production value in 2016 exceeding $\$ 600$ million (California Agricultural Statistics Service 2004, 2016; U.S. Department of Agriculture-National Agricultural Statistics Service 2017). In California, as mandarin fruit production increases, cold storage of fruit before packing has become a common practice to retain quality and expand marketing opportunities. After initial presorting, mandarin fruit may be stored at 4 to $8^{\circ} \mathrm{C}$ for up to several weeks before packing and shipping to the market. Extended storage, however, can increase the risk for development of postharvest fruit rot diseases.

Previously, we conducted a survey in citrus packinghouses to determine the major postharvest diseases affecting stored mandarin fruit, and we found that, in addition to the historically common green mold (caused by Penicillium digitatum), blue mold (caused by Penicillium italicum), and sour rot (caused by Geotrichum citri-aurantii), gray mold (caused by Botrytis cinerea) had become one of the emerging diseases in California (Saito and Xiao 2017). Control of citrus postharvest diseases in California is largely dependent on the use of postharvest fungicides (Kanetis et al. 2008; McKay et al. 2012; Smilanick et al. 1997, 2006a, 2008). Fungicide programs in citrus packinghouses

${ }^{\dagger}$ Corresponding author: C. L. Xiao; Chang-Lin.Xiao@usda.gov

Funding: This research was funded in part by California Research Board grant 5400-151.

*The $\boldsymbol{e}$-Xtra logo stands for "electronic extra" and indicates that a supplementary table is published online.

The author(s) declare no conflict of interest.

Accepted for publication 1 October 2019.

This article is in the public domain and not copyrightable. It may be freely reprinted with customary crediting of the source. The American Phytopathological Society, 2020 were primarily targeting green mold, blue mold, and sour rot before gray mold became a significant threat to stored mandarins (Holmes and Eckert 1999; Kanetis et al. 2008; Smilanick and Mansour 2007; Smilanick et al. 1997, 2008). Several fungicides have been registered for postharvest use on citrus in California, including azoxystrobin, fludioxonil, pyrimethanil, and thiabendazole, that are known to be effective against $B$. cinerea. However, $B$. cinerea can infect many other economically important crops, and it is a high-risk pathogen for the development of fungicide resistance that can result in the failure of disease control (Leroux 2004). In the Central Valley of California, citrus trees are often planted next to table grapes, blueberries, or other crops that are susceptible to gray mold. Resistance to multiple fungicides is commonly present in populations of $B$. cinerea in these crops (Saito et al. 2016, 2019). In a previous study, we examined resistance of $200 \mathrm{~B}$. cinerea isolates from decayed mandarin fruit to four citrus postharvest fungicides. Although there was no resistance to fludioxonil, $90.5,82$, and $65.5 \%$ of the isolates were resistant to azoxystrobin, pyrimethanil, and thiabendazole, respectively. Furthermore, the latter three fungicides failed to control gray mold on fruit inoculated with their respective resistant strains, although fludioxonil was effective against all fungicide-resistant phenotypes tested on mandarin fruit. Thus, fludioxonil seemed to be a viable tool to control gray mold on mandarin fruit in California (Saito and Xiao 2018). An in vitro study done by others demonstrated that $B$. cinerea isolates with dual resistance to thiabendazole and pyrimethanil can rapidly develop resistance to fludioxonil on consecutive exposure to the fungicide (Jurick et al. 2017). Therefore, additional fungicides with different modes of action are needed to control postharvest gray mold of citrus fruit and manage fungicide resistance in $B$. cinerea populations.

Natamycin is a naturally occurring antimycotic compound derived from the common soil microorganism Streptomyces natalensis and some other species of the genus Streptomyces (Oostendorp 1981). It has been commonly used in the food industry as an additive to reduce the growth of yeasts and molds on the surface of cheese and other nonsterile food products, such as meat and sausages, and it had limited use in human and veterinary medicine as a topical treatment for certain fungal infections (Delves-Broughton et al. 2005). Natamycin inhibits fungal growth by binding to ergosterol without permeabilizing the plasma 
membrane (te Welscher et al. 2008, 2010). In plant pathology, natamycin has commonly been used in selective media for isolating Phytophthora species (Eckert and Tsao 1962; Tsao and Ocano 1969). Natamycin (trade name BioSpectra) was registered in the United States in 2016 to control postharvest diseases on certain fresh fruits, including citrus (U.S. Environmental Protection Agency 2016). It is classified as a biofungicide by the Environmental Protection Agency, and therefore, it is exempt from residue tolerance in the United States (U.S. Environmental Protection Agency 2012). Natamycin belongs to the polyene group of fungicides with a Fungicide Resistance Action Committee code 48, and its mode of action differs from those of other citrus postharvest fungicides (Fungicide Resistance Action Committee 2018). Natamycin has been shown to be effective in controlling various citrus postharvest diseases, such as green mold, blue mold, and sour rot (Yigiter et al. 2014). However, the effectiveness of natamycin for control of gray mold has not previously been documented. It is also unknown whether natamycin is effective against $B$. cinerea strains resistant to other fungicides that are commonly used to control gray mold.

Therefore, the objectives of this study were to (i) test the sensitivity of $B$. cinerea isolates to natamycin, (ii) determine whether there is cross-resistance between selected citrus postharvest fungicides and natamycin, and (iii) evaluate the efficacy of natamycin in controlling gray mold of citrus fruit after inoculation with $B$. cinerea isolates with different fungicide resistance phenotypes.

\section{Materials and Methods}

B. cinerea isolates. Detailed information about collection, isolation, and identification of isolates was described previously (Saito and Xiao 2017, 2018). Briefly, decayed mandarin fruit was sampled from citrus packinghouses in the Central Valley of California in 2015 and 2016. After initial identification of Botrytis spp. based on morphological characteristics, all isolates were single-spore cultured and further identified to species based on sequence analysis. Sixty-four $B$. cinerea isolates representing five fungicide resistance phenotypes (Saito and Xiao 2018) were selected for establishing the sensitivity ranges of $B$. cinerea isolates to natamycin, and these isolates had not been exposed to natamycin previously (Table 1 ).

In vitro sensitivity to natamycin. Technical grade of natamycin (Sigma-Aldrich) was used for the preparation of a stock solution $(5,000 \mu \mathrm{g} / \mathrm{ml})$ in $85 \%$ (vol/vol) dimethyl sulfoxide:water (Streekstra et al. 2016; van Leeuwen et al. 2013). The stock solution was freshly made prior to each use. Sensitivities to natamycin were determined for conidial germination and mycelial growth. For both tests, effective concentrations inhibiting $50 \%$ of fungal growth or germination ( $\mathrm{EC}_{50}$ values) and minimum inhibitory concentrations (MICs) where no fungal growth was present were determined for each isolate.

For the conidial germination assay, conidia from 1- to 2-week-old potato dextrose agar (PDA; Difco Laboratories) cultures were suspended in sterile distilled water, and the suspension was filtered through sterile gauze and adjusted to approximately $1.0 \times 10^{5}$ conidia per milliliter. Conidial suspensions were prepared immediately prior to the experiment and placed on ice until use. For each isolate, an aliquot of $10 \mu \mathrm{l}$ of conidial suspension was streaked onto 6-cmdiameter PDA plates amended with natamycin at $0.2,0.3,0.4,0.5$, $0.6,0.7$, or $1.0 \mu \mathrm{g} / \mathrm{ml}$. For each concentration, two replicates of plates were used. Plates without natamycin were used as controls. After 14 to $16 \mathrm{~h}$ at $20^{\circ} \mathrm{C}$ in the dark, the number of germinated conidia of at least 100 conidia on each plate was counted under a microscope. Spores with germ tubes more than twice the diameter of the spore were considered germinated. All isolates were evaluated in two separate experiments. Germination percentage was calculated after dividing the average number of germinated conidia by the total number of conidia examined.

For the mycelial growth assay, 6.5-mm-diameter plugs from the leading edge of 3- to 4-day-old PDA cultures were transferred singly to the center of 9-cm-diameter petri dishes amended with natamycin at $0.5,1.0,1.5,2.0,3.0,5.0$, or $10.0 \mu \mathrm{g} / \mathrm{ml}$. Plates without natamycin were used as controls. After $60 \mathrm{~h}$ at $20^{\circ} \mathrm{C}$ in dark, colony diameters were measured in two perpendicular directions, and relative growth rates (percentages) was calculated compared with the controls. All isolates were evaluated in two separate experiments.

Cross-sensitivity between natamycin and other fungicides. In our previous study, resistance to azoxystrobin (Azo), fludioxonil (Flu), pyrimethanil (Pym), and thiabendazole (Tbz) was determined for $B$. cinerea populations from mandarin fruit (Saito and Xiao 2018). In this study, to determine whether there is cross-sensitivity (resistance) between natamycin and other modes of action fungicides, $\mathrm{EC}_{50}$ values of natamycin for conidial germination and mycelial growth were compared for the following pairs: phenotypes $\mathrm{Azo}^{\mathrm{R}} \mathrm{Pym}^{\mathrm{R}} \mathrm{Flu}^{\mathrm{S}} \mathrm{Tbz}^{\mathrm{R}}$ versus $\mathrm{Azo}^{\mathrm{R}} \mathrm{Pym}^{\mathrm{R}} \mathrm{Flu}^{\mathrm{S}} \mathrm{Tbz}$ ( Tbz resistant versus Tbz sensitive); phenotypes $\mathrm{Azo}^{\mathrm{R}} \mathrm{Pym}^{\mathrm{R}} \mathrm{Flu}^{\mathrm{S}} \mathrm{Tbz}^{\mathrm{R}}$ versus $\mathrm{Azo}^{\mathrm{R}} \mathrm{Pym}^{\mathrm{S}} \mathrm{Flu}^{\mathrm{S}} \mathrm{Tbz}^{\mathrm{R}}$ (Pym resistant versus Pym sensitive); phenotypes $\mathrm{Azo}^{\mathrm{R}} \mathrm{Pym}^{\mathrm{R}} \mathrm{Flu}^{\mathrm{S}} \mathrm{Tbz}^{\mathrm{S}}$ versus $\mathrm{Azo}^{\mathrm{R}} \mathrm{Pym}^{\mathrm{S}} \mathrm{Flu}^{\mathrm{S}} \mathrm{Tbz}^{\mathrm{S}}$ (Pym resistant versus Pym sensitive); phenotypes $\mathrm{Azo}^{\mathrm{R}} \mathrm{Pym}^{\mathrm{S}} \mathrm{Flu}^{\mathrm{S}} \mathrm{Tbz}^{\mathrm{R}}$ versus $\mathrm{Azo}^{\mathrm{R}} \mathrm{Pym}^{\mathrm{S}} \mathrm{Flu}^{\mathrm{S}} \mathrm{Tbz}^{\mathrm{S}}$ (Tbz resistant versus Tbz sensitive); and phenotypes $\mathrm{Azo}^{\mathrm{R}} \mathrm{Pym}^{\mathrm{S}} \mathrm{Flu}^{\mathrm{S}} \mathrm{Tbz}^{\mathrm{S}}$ versus $\mathrm{Azo}^{\mathrm{S}} \mathrm{Pym}^{\mathrm{S}} \mathrm{Flu}^{\mathrm{S}} \mathrm{Tbz}^{\mathrm{S}}$ (Azo resistant versus Azo sensitive).

Gray mold control tests with inoculated mandarin fruit. Formulated natamycin (BioSpectra 100SC; $10.34 \%$ a.i.; Pace International) was used in efficacy tests to control gray mold of mandarin fruit inoculated with isolates of various fungicide resistance phenotypes in this study. The highest (i.e., $920 \mu \mathrm{g} / \mathrm{ml}$ ) and the lowest (i.e., $460 \mu \mathrm{g} / \mathrm{ml}$ ) label rates were used, and these are hereafter referred to as "high" and "low", respectively.

In the first experiment, mandarin fruit (cultivar Tango) from a local packinghouse that had not been treated after harvest with any fungicides was used. Procedures were followed as described previously (Saito and Xiao 2018) with slight modifications. Briefly, fruit was surface disinfected by dipping into $100 \mu \mathrm{g} / \mathrm{ml}$ of sodium hypochlorite for $2 \mathrm{~min}$, rinsed with sterile water three times, and allowed to air dry. A wound (4.8 $\mathrm{mm}$ in diameter and $6 \mathrm{~mm}$ deep) was made at the equator of each fruit using a sterile steel nail, simulating a stab wound caused by a stem of mandarin fruit that occurs during harvest and postharvest handling. In the first experiment, $5 \mu$ l of conidial suspension $\left(1.0 \times 10^{6}\right.$ spores per milliliter) of five $B$. cinerea isolates representing five fungicide resistance phenotypes (Table 2 ) was pipetted into the wounds. Inoculated fruit was stored in a plastic container at $20^{\circ} \mathrm{C}$ for 1 or $24 \mathrm{~h}$ and then, placed in a plastic strainer that was gently dipped in the fungicide solution for $30 \mathrm{~s}$. A water dip was used as control. For each isolate, 20 fruits for each of three replicates were

Table 1. Fungicide resistance phenotypes of Botrytis cinerea isolates used in this study and average effective concentrations inhibiting $50 \%$ of fungal growth or germination ( $\mathrm{EC}_{50}$ values) of natamycin for conidial germination and mycelial growth

\begin{tabular}{|c|c|c|c|}
\hline \multirow[b]{2}{*}{ Phenotype $^{y}$} & \multirow[b]{2}{*}{ Number of isolates } & \multicolumn{2}{|c|}{ Average $\mathrm{EC}_{50}$ values $\pm \mathrm{SD}(\mu \mathrm{g} / \mathrm{ml})^{\mathrm{z}}$} \\
\hline & & Conidial germination & Mycelial growth \\
\hline$\overline{\mathrm{Azo}^{\mathrm{R}} \mathrm{Pym}^{\mathrm{R}} \mathrm{Flu}^{\mathrm{S}} \mathrm{Tbz}^{\mathrm{R}}}$ & 31 & $0.448 \pm 0.242 \mathrm{a}$ & $1.574 \pm 0.242 \mathrm{a}$ \\
\hline $\mathrm{Azo}^{\mathrm{R}} \mathrm{Pym}^{\mathrm{R}} \mathrm{Flu}^{\mathrm{S}} \mathrm{Tbz}^{\mathrm{S}}$ & 13 & $0.423 \pm 0.049 a$ & $1.504 \pm 0.188 \mathrm{a}$ \\
\hline $\mathrm{Azo}^{\mathrm{R}} \mathrm{Pym}^{\mathrm{S}} \mathrm{Flu}^{\mathrm{S}} \mathrm{Tbz}^{\mathrm{R}}$ & 5 & $0.455 \pm 0.051 \mathrm{a}$ & $1.787 \pm 0.178 \mathrm{a}$ \\
\hline $\mathrm{Azo}^{\mathrm{R}} \mathrm{Pym}^{\mathrm{S}} \mathrm{Flu}^{\mathrm{S}} \mathrm{Tbz}^{\mathrm{S}}$ & 5 & $0.441 \pm 0.032 \mathrm{a}$ & $1.507 \pm 0.382 \mathrm{a}$ \\
\hline $\mathrm{Azo}^{\mathrm{S}} \mathrm{Pym}^{\mathrm{S}} \mathrm{Flu}^{\mathrm{S}} \mathrm{Tbz}^{\mathrm{S}}$ & 10 & $0.452 \pm 0.065 \mathrm{a}$ & $1.620 \pm 0.252 \mathrm{a}$ \\
\hline
\end{tabular}

${ }^{y}$ Fungicide resistance of each isolate was determined previously (Saito and Xiao 2018). Azo, azoxystrobin; Flu, fludioxonil; Pym, pyrimethanil; R, resistant; S, sensitive; Tbz, thiabendazole.

${ }^{\mathrm{z}}$ Values within the same column followed by the same letter are not significantly different according to Tukey's test $(P \geq 0.05)$. SD, standard deviation. 
used per treatment. Fruit was allowed to air dry and then placed into plastic fruit trays inside plastic containers containing a paper towel placed at the bottom of the container and saturated with sterile water to establish a high RH. The plastic container was sealed with a lid and stored in the dark at $5^{\circ} \mathrm{C}$. Gray mold readily developed on inoculated fruit, and after 2 weeks of incubation, all inoculated fruits in the control were decayed, but lesions on the fruit were still measurable. Thus, to measure lesion sizes on inoculated fruit before the entire individual fruit was decayed, disease was evaluated after 2 weeks of incubation. Lesion sizes were measured at two perpendicular directions using a caliper, and disease incidence was recorded. This experiment was performed twice.

In the second experiment, an isolate sensitive to all fungicides was used in inoculations to evaluate the efficacy of natamycin in selected inoculation-treatment timings. Preparation of fruit, inoculum, and fruit storage were done as described above. Fruit was treated 1, 6, or $12 \mathrm{~h}$ after inoculation. This experiment was performed twice.

In the third experiment, an isolate sensitive to all fungicides was used in inoculations to directly compare the efficacy of natamycin and that of fludioxonil. Formulated fludioxonil (FDL 230SC; $20.4 \%$ a.i.; fludioxonil; Pace International) at the recommended concentration of $1.25 \mathrm{ml} / \mathrm{liter}$ was used. Preparation of fruit, inoculum, and fruit storage were done as described above. Fruit was treated $1 \mathrm{~h}$ after inoculation. To evaluate the efficacy of fungicides for an extended period of time, disease was evaluated at 2, 3, and 4 weeks after storage. This experiment was performed twice.

Statistical analysis. All statistical analyses were conducted in SAS (version 9.4; SAS Institute, Inc.). $\mathrm{EC}_{50}$ values of natamycin were determined using PROC LOGISTIC.

To determine whether there was cross-resistance between natamycin and azoxystrobin, pyrimethanil, or thiabendazole, an unequal variance $t$ test was performed using PROC TTEST to compare the mean $\mathrm{EC}_{50}$ values of natamycin between the paired fungicide resistance phenotypes $(P<0.05)$. Analysis of variance was also performed using PROC ANOVA followed by Tukey's tests to compare the mean $\mathrm{EC}_{50}$ values of natamycin across five resistance phenotypes $(P<0.05)$.

The percentage data from the decay control tests were arcsine square root transformed before analysis. Analysis of variance using PROC GLIMMIX in SAS was performed with treatment and/or inoculation-treatment timing as fixed effects and experiment run as a random effect, and mean separation was made by Tukey's test. For the first experiment, a three-way analysis of variance was performed to determine the effects of each of the three variables (fungicide resistance phenotype, time from inoculation to treatment, and concentration of natamycin) and their interactions on the incidence and severity of gray mold on detached mandarin fruit.

\section{Results}

Sensitivity of $B$. cinerea isolates to natamycin and crosssensitivity between natamycin and other fungicides. $\mathrm{EC}_{50}$ values of natamycin for 64 isolates were from 0.324 to $0.567 \mu \mathrm{g} / \mathrm{ml}$ with a mean ( \pm standard deviation [SD]) of $0.444 \pm 0.055 \mu \mathrm{g} / \mathrm{ml}$ for conidial germination and from 1.021 to $2.007 \mu \mathrm{g} / \mathrm{ml}$ with a mean $( \pm$ SD) of $1.578 \pm 0.245 \mu \mathrm{g} / \mathrm{ml}$ for mycelial growth. For both conidial germination and mycelial growth, the sensitivities followed unimodal distribution of frequencies (Fig. 1). The MICs for conidial germination were $0.7 \mu \mathrm{g} / \mathrm{ml}$ for 50 isolates and $1.0 \mu \mathrm{g} / \mathrm{ml}$ for 14 isolates. The MICs for mycelial growth were $5.0 \mu \mathrm{g} / \mathrm{ml}$ for 21 isolates and $10.0 \mu \mathrm{g} / \mathrm{ml}$ for 43 isolates.

There were no significant differences in average $\mathrm{EC}_{50}$ values among the five pairs of different fungicide resistance phenotypes according to the unequal variance $t$ test (Supplementary Table S1). Analysis of variance also indicated that there were no significant differences in average $\mathrm{EC}_{50}$ values among the five resistance phenotypes $(P=0.66$ for conidial germination and $P=0.24$ for mycelial growth) (Table 1).

Gray mold control tests with inoculated mandarin fruit. Natamycin at both low and high rates significantly reduced disease incidence and severity (lesion size) on fruit inoculated with one of five $B$. cinerea isolates, regardless of fungicide resistance phenotype and time that the fungicide was applied after inoculation in comparison with the nontreated control (Tables 2 and 3). When natamycin was applied $1 \mathrm{~h}$ after inoculation, low and high rates reduced disease incidence on average by 84.0 and $89.5 \%$, respectively, and lesion size by 91.6 and $94.7 \%$, respectively, relative to the nontreated control (Table 2). With a 24-h delay in treatment, natamycin at both low and high rates also significantly reduced gray mold incidence and
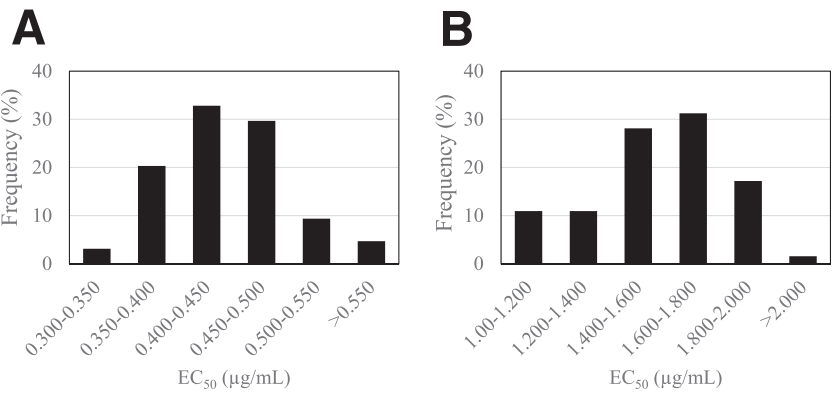

Fig. 1. Distribution of effective concentrations inhibiting $50 \%$ of fungal growth or germination ( $\mathrm{EC}_{50}$ values) of natamycin for $\mathbf{A}$, conidial germination and $\mathbf{B}$, mycelial growth of 64 Botrytis cinerea isolates.

Table 2. Efficacy of natamycin in controlling gray mold of mandarin fruit caused by Botrytis cinerea isolates with five different fungicide resistance phenotypes

\begin{tabular}{|c|c|c|c|c|c|c|}
\hline \multirow{2}{*}{$\begin{array}{l}\text { Time from inoculation to } \\
\text { treatment }^{\mathrm{w}} \text { and phenotype }\end{array}$} & \multicolumn{3}{|c|}{ Incidence $(\%)^{\mathbf{y}}$} & \multicolumn{3}{|c|}{ Severity $(\mathbf{m m})^{\mathbf{y}}$} \\
\hline & Control & Low rate & High ratez & Control & Low rate & High rate \\
\hline \multicolumn{7}{|l|}{$1 \mathrm{~h}$} \\
\hline $\mathrm{Azo}^{\mathrm{R}} \mathrm{Pym}^{\mathrm{R}} \mathrm{Flu}^{\mathrm{S}} \mathrm{Tbz}^{\mathrm{R}}$ & 100 a A & $19.2 \mathrm{~b} \mathrm{~A}$ & $8.3 \mathrm{c} \mathrm{AB}$ & 29.6 a A & $2.7 \mathrm{~b} \mathrm{~A}$ & $1.2 \mathrm{c} \mathrm{B}$ \\
\hline $\mathrm{Azo}^{\mathrm{R}} \mathrm{Pym}^{\mathrm{R}} \mathrm{Flu}^{\mathrm{S}} \mathrm{Tbz}^{\mathrm{S}}$ & 100 a A & $16.7 \mathrm{~b} \mathrm{~A}$ & 11.7 c AB & 29.6 a A & $2.5 \mathrm{~b} \mathrm{~A}$ & $1.8 \mathrm{~b} \mathrm{AB}$ \\
\hline $\mathrm{Azo}^{\mathrm{R}} \mathrm{Pym}^{\mathrm{S}} \mathrm{Flu}^{\mathrm{S}} \mathrm{Tbz}^{\mathrm{R}}$ & 100 a A & $11.7 \mathrm{~b} \mathrm{~A}$ & $6.7 \mathrm{c} \mathrm{B}$ & 28.4 a B & $1.8 \mathrm{~b} \mathrm{~A}$ & 0.9 с B \\
\hline $\mathrm{Azo}^{\mathrm{R}} \mathrm{Pym}^{\mathrm{S}} \mathrm{Flu}^{\mathrm{S}} \mathrm{Tbz}^{\mathrm{S}}$ & 100 a A & $15.8 \mathrm{~b} \mathrm{~A}$ & $17.5 \mathrm{c} \mathrm{A}$ & 27.8 a B & $2.5 \mathrm{~b} \mathrm{~A}$ & $2.6 \mathrm{~b} \mathrm{~A}$ \\
\hline $\mathrm{Azo}^{\mathrm{S}} \mathrm{Pym}^{\mathrm{S}} \mathrm{Flu}^{\mathrm{S}} \mathrm{Tbz}^{\mathrm{S}}$ & 100 a A & $16.7 \mathrm{~b} \mathrm{~A}$ & $8.3 \mathrm{c} \mathrm{AB}$ & 30.6 a A & $2.8 \mathrm{~b} \mathrm{~A}$ & $1.2 \mathrm{c} \mathrm{B}$ \\
\hline \multicolumn{7}{|l|}{$24 \mathrm{~h}$} \\
\hline $\mathrm{Azo}^{\mathrm{R}} \mathrm{Pym}^{\mathrm{R}} \mathrm{Flu}^{\mathrm{S}} \mathrm{Tbz}^{\mathrm{R}}$ & 100 a A & $70.8 \mathrm{~b} \mathrm{~A}$ & $60.8 \mathrm{c} \mathrm{A}$ & 38.6 a B & $13.7 \mathrm{~b} \mathrm{~A}$ & $11.3 \mathrm{~b} \mathrm{~B}$ \\
\hline $\mathrm{Azo}^{\mathrm{R}} \mathrm{Pym}^{\mathrm{R}} \mathrm{Flu}^{\mathrm{S}} \mathrm{Tbz}^{\mathrm{S}}$ & 100 a A & $75.0 \mathrm{~b} \mathrm{~A}$ & $73.3 \mathrm{~b} \mathrm{~A}$ & 37.8 a B & $17.4 \mathrm{~b} \mathrm{~A}$ & $16.9 \mathrm{~b} \mathrm{~A}$ \\
\hline $\mathrm{Azo}^{\mathrm{R}} \mathrm{Pym}^{\mathrm{S}} \mathrm{Flu}^{\mathrm{S}} \mathrm{Tbz}^{\mathrm{R}}$ & 100 a A & $65.0 \mathrm{~b} \mathrm{~A}$ & $69.2 \mathrm{~b} \mathrm{~A}$ & 37.7 a B & $14.4 \mathrm{~b} \mathrm{~A}$ & $14.8 \mathrm{~b} \mathrm{~A}$ \\
\hline $\mathrm{Azo}^{\mathrm{R}} \mathrm{Pym}^{\mathrm{S}} \mathrm{Flu}^{\mathrm{S}} \mathrm{Tbz}^{\mathrm{S}}$ & 100 a A & $68.3 \mathrm{~b} \mathrm{~A}$ & $67.5 \mathrm{~b} \mathrm{~A}$ & 40.4 a A & $16.8 \mathrm{~b} \mathrm{~A}$ & $14.2 \mathrm{~b} \mathrm{AB}$ \\
\hline $\mathrm{Azo}^{\mathrm{S}} \mathrm{Pym}^{\mathrm{S}} \mathrm{Flu}^{\mathrm{S}} \mathrm{Tbz}^{\mathrm{S}}$ & 100 a A & $72.5 \mathrm{~b} \mathrm{~A}$ & $60.8 \mathrm{c} \mathrm{A}$ & 41.3 a A & $17.5 \mathrm{~b} \mathrm{~A}$ & $14.5 \mathrm{c} \mathrm{A}$ \\
\hline
\end{tabular}

${ }^{w}$ Inoculated fruit was stored at $20^{\circ} \mathrm{C}$ for 1 or $24 \mathrm{~h}$ before the treatment.

x Fungicide resistance of each isolate was determined previously (Saito and Xiao 2018). Azo, azoxystrobin; Flu, fludioxonil; Pym, pyrimethanil; R, resistant; $\mathrm{S}$, sensitive; Tbz, thiabendazole.

y Incidence data (percentage) were arcsine square root transformed before analysis, with the actual percentage shown in the table. Lesion size (millimeters) was measured in perpendicular directions. Values followed by the same lowercase letters within a row or values followed by the same uppercase letters within a column for each inoculation-treatment timing are not significantly different according to Tukey's test $(P \geq 0.05)$.

${ }^{\mathrm{z}}$ Low-rate $(460 \mu \mathrm{g} / \mathrm{ml})$ and high-rate $(920 \mu \mathrm{g} / \mathrm{ml})$ concentrations of natamycin were used. 
severity compared with the nontreated control, but the efficacy was compromised, with average reductions of 29.7 and $33.7 \%$, respectively, in disease incidence and 59.3 and $63.3 \%$, respectively, in severity relative to the nontreated control (Table 2 ).

In the second experiment, delayed natamycin treatments $(1,6$, and $12 \mathrm{~h}$ after inoculation) were tested. Low and high rates significantly reduced disease incidence and severity compared with the nontreated control at all timings (Table 4). For both rates, there were no significant differences in disease incidence and severity between treatments applied 1 or $6 \mathrm{~h}$ after inoculation. However, applications after $12 \mathrm{~h}$ were significantly less effective (Table 4).

In the third experiment, efficacy of natamycin and fludioxonil was evaluated for an extended period of time. On the 2-week evaluation, low and high rates of natamycin and fludioxonil significantly reduced disease incidence and severity compared with the nontreated control (Table 5). On the third week, most of the fruit from the nontreated control was completely decayed, the lesion size was not measurable, and thus, the fruit was excluded from further evaluation. Although lesion sizes remained relatively small on high rate of natamycin- and fludioxonil-treated fruit, the increase of disease incidence was observed from the third week (Table 5). On the fourth week, although lesion sizes on most of fruit that had started to show decay symptoms remained small, disease incidence increased for all treatments (Table 5).

\section{Discussion}

In this study, we demonstrated that natamycin was highly effective in controlling gray mold caused by $B$. cinerea on mandarin fruit, regardless of fungicide resistance phenotype of the pathogen. Although natamycin has been demonstrated to effectively control gray mold in table grapes (He et al. 2019), that research included only one B. cinerea isolate, and it was conducted only in laboratory conditions, which do not represent commercial storage conditions. To the best of our knowledge, this is the first report of sensitivity of $B$. cinerea to natamycin and its effectiveness in controlling gray mold caused by $B$. cinerea, including strains resistant to other modes of action fungicides. The 64 isolates tested for sensitivity to natamycin in this study were not exposed to this compound prior to collection, and the isolates from each fungicide-resistance phenotype group were

Table 3. Analysis of variance of the effects of the phenotype $(P)$, time from inoculation to treatment $(T)$, concentration of natamycin $(C)$, and interactions among variables on the incidence and severity of gray mold on mandarin fruit (Table 2)

\begin{tabular}{lcrrrrr}
\hline & & \multicolumn{2}{c}{ Incidence } & & \multicolumn{2}{c}{ Severity } \\
\cline { 3 - 4 } Variables & df $^{\mathbf{z}}$ & $\boldsymbol{F}$ value & $\boldsymbol{P}$ value & & $\boldsymbol{F}$ value & $\boldsymbol{P}$ value \\
\hline$P$ & 4 & 1.49 & 0.2068 & 6.3 & 0.0001 \\
$T$ & 1 & 733.68 & $<0.0001$ & & $1,804.92$ & $<0.0001$ \\
$C$ & 2 & $1,524.98$ & $<0.0001$ & & $3,624.28$ & $<0.0001$ \\
$P \times T$ & 4 & 0.91 & 0.4598 & & 3.64 & 0.0073 \\
$P \times C$ & 8 & 1.58 & 0.1367 & & 2.29 & 0.0239 \\
$T \times C$ & 2 & 183.83 & $<0.0001$ & & 13.93 & $<0.0001$ \\
$P \times T \times C$ & 8 & 0.75 & 0.6458 & & 2.12 & 0.0372 \\
\hline $\mathrm{z}$ df degre of freedom & & & & &
\end{tabular}

$\mathrm{z}$ df, degree of freedom. randomly selected. Thus, the sensitivity to natamycin established in this study could be considered a baseline sensitivity in $B$. cinerea populations from mandarin fruit in California.

Natamycin reduced conidial germination and mycelial growth of B. cinerea. $\mathrm{EC}_{50}$ values of natamycin for conidial germination were three- to fourfold lower than those for mycelial growth, and MICs for conidial germination were fivefold or more lower than those for mycelial growth, indicating that conidial germination was more sensitive than mycelial growth. MICs of natamycin were examined previously in various fungi. For instance, MICs of 26 fungal isolates, including the genera Penicillium, Aspergillus, and Cladosporium, collected from cheese warehouses ranged from 1.0 to $12.0 \mu \mathrm{g} / \mathrm{ml}$ (de Boer and Stolk-Horsthuis 1977). In a conidial germination assay, MICs of Alternaria alternata isolates and Fusarium sp. isolates causing eye infection in humans were 2 and 4 to $8 \mu \mathrm{g} / \mathrm{ml}$, respectively (Al-Hatmi et al. 2016; Ando and Takatori 1987), whereas in a mycelial growth assay, the MIC of A. alternata and Fusarium semitectumby was $20 \mu \mathrm{g} / \mathrm{ml}$ (Cong et al. 2007). The MICs of B. cinerea isolates examined in this study were comparable with those from previous studies on other fungi. Sensitivity of Colletotrichum acutatum isolates collected from strawberry to natamycin has been reported, and the average $\mathrm{EC}_{50}$ value was $0.973 \mu \mathrm{g} / \mathrm{ml}$, ranging from 0.526 to $1.996 \mu \mathrm{g} / \mathrm{ml}$ for mycelial growth (Haack et al. 2018), which is comparable with that obtained from $B$. cinerea isolates in this study.

For $B$. cinerea isolates that are sensitive to the respective fungicides, pyrimethanil, fludioxonil, and thiabendazole were effective in controlling gray mold, and the average disease incidence rates on mandarin fruit treated with pyrimethanil, fludioxonil, and thiabendazole were 6.8, 13.0, and 0.6\%, respectively (Saito and Xiao 2018). In this study, the average disease incidence rates on fruit treated with natamycin at low and high rates were 16.0 and $10.5 \%$, respectively, regardless of fungicide-resistance phenotypes. Our previous study

Table 5. Efficacy of natamycin and fludioxonil in controlling gray mold of mandarin fruit after extended cold storage ${ }^{y}$

\begin{tabular}{|c|c|c|c|c|}
\hline \multirow[b]{2}{*}{ Storage period, weeks } & \multicolumn{4}{|c|}{ Treatment } \\
\hline & Control & Low & High & Flu \\
\hline \multicolumn{5}{|l|}{2} \\
\hline Severity $(\mathrm{mm})$ & $36.4 \mathrm{a}$ & $3.4 \mathrm{~b}$ & $1.4 \mathrm{c}$ & $0.8 \mathrm{c}$ \\
\hline Incidence (\%) & $100 \mathrm{a}$ & $14.2 \mathrm{~b}$ & $6.7 \mathrm{bc}$ & $3.3 \mathrm{c}$ \\
\hline \multicolumn{5}{|l|}{3} \\
\hline Severity (mm) & n.d. ${ }^{\mathrm{z}}$ & $21.6 \mathrm{a}$ & $10.3 \mathrm{~b}$ & $5.7 \mathrm{c}$ \\
\hline Incidence $(\%)$ & & $74.2 \mathrm{a}$ & $36.7 \mathrm{~b}$ & $24.2 \mathrm{c}$ \\
\hline \multicolumn{5}{|l|}{ 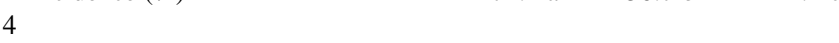 } \\
\hline Severity (mm) & n.d. & n.d. & n.d. & n.d. \\
\hline Incidence $(\%)$ & & $97.5 \mathrm{a}$ & $75.0 \mathrm{~b}$ & $68.3 \mathrm{~b}$ \\
\hline
\end{tabular}

y Fruit inoculated with Botrytis cinerea isolate $\mathrm{X} 2305$ was stored at $20^{\circ} \mathrm{C}$ for 1 $\mathrm{h}$ before treatment. Incidence data (percentage) were arcsine square root transformed before the analysis, with the actual percentage shown in the table. Lesion size (millimeters) was measured in perpendicular directions. Values followed by the same lowercase letters within a row are not significantly different according to Tukey's test $(P \geq 0.05)$. Low-rate $(460 \mu \mathrm{g} / \mathrm{ml})$ and high-rate $(920 \mu \mathrm{g} / \mathrm{ml})$ concentrations of natamycin and fludioxonil (Flu; $255 \mu \mathrm{g} / \mathrm{ml}$ ) were used.

${ }^{\mathrm{z}}$ n.d., not determined.

Table 4. Efficacy of natamycin in controlling gray mold of mandarin fruit when applied 1, 6, or $12 \mathrm{~h}$ after inoculation

\begin{tabular}{|c|c|c|c|c|c|c|}
\hline \multirow{2}{*}{$\begin{array}{l}\text { Time from inoculation } \\
\text { to treatment, } \mathbf{h}^{\mathbf{x}}\end{array}$} & \multicolumn{3}{|c|}{ Incidence $(\%)^{\mathrm{y}}$} & \multicolumn{3}{|c|}{ Severity $(\mathbf{m m})^{y}$} \\
\hline & Control & Low $^{\mathrm{z}}$ & High $^{\mathbf{z}}$ & Control & Low $^{z}$ & High $^{z}$ \\
\hline 1 & 100 a A & 19.2 b B & 10.8 c B & 29.4 a C & $3.3 \mathrm{~b} \mathrm{~B}$ & $1.6 \mathrm{~b} \mathrm{~B}$ \\
\hline 6 & 100 a A & $35.0 \mathrm{~b} \mathrm{AB}$ & $18.3 \mathrm{c} \mathrm{B}$ & 31.9 a B & $5.1 \mathrm{~b} \mathrm{~B}$ & $2.6 \mathrm{c} \mathrm{B}$ \\
\hline 12 & 100 a A & $47.5 \mathrm{~b} \mathrm{~A}$ & $38.3 \mathrm{~b} \mathrm{~A}$ & 36.8 a $\mathrm{A}$ & $10.3 \mathrm{~b} \mathrm{~A}$ & $8.0 \mathrm{c} \mathrm{A}$ \\
\hline
\end{tabular}

${ }^{\mathrm{x}}$ Fruit inoculated with Botrytis cinerea isolate $\mathrm{X} 2305$ was stored at $20^{\circ} \mathrm{C}$ for 1,6 , or $12 \mathrm{~h}$ before treatment.

${ }^{y}$ Incidence data (percentage) were arcsine square root transformed before the analysis, with the actual percentage shown in the table. Lesion size (millimeters) was measured in perpendicular directions. Values followed by the same lowercase letters within a row or values followed by the same uppercase letters within a column for each inoculation-treatment timing are not significantly different according to Tukey's test $(P \geq 0.05)$.

${ }^{\mathrm{z}}$ Low-rate $(460 \mu \mathrm{g} / \mathrm{ml})$ and high-rate $(920 \mu \mathrm{g} / \mathrm{ml})$ concentrations of natamycin were used. 
indicated that $B$. cinerea from mandarins had developed resistance to azoxystrobin, pyrimethanil, and thiabendazole, but no resistance to fludioxonil was detected (Saito and Xiao 2018). The availability of B. cinerea isolates resistant to azoxystrobin, pyrimethanil, and thiabendazole allowed us to examine whether there is cross-resistance between natamycin and these three citrus postharvest fungicides belonging to different modes of action. We were not able to examine potential cross-resistance with fludioxonil, because fludioxonil resistance has not been detected in the mandarin populations (Saito and Xiao 2018). In our previous study, fludioxonil was effective in controlling the current fungicide-resistant populations of $B$. cinerea associated with mandarin fruit (Saito and Xiao 2018). In this study, the efficacy of high rate of natamycin was as effective as that of fludioxonil. Because natamycin has a different mode of action from other citrus postharvest fungicides, natamycin could be integrated into postharvest fungicide programs for control of gray mold and management of fungicide resistance in $B$. cinerea.

It has previously been demonstrated that natamycin effectively controlled green mold and blue mold on orange and lemon (Yigiter et al. 2014). Natamycin can be a promising tool for the control of major postharvest diseases of citrus in California. The efficacy of natamycin can be compromised if the application is delayed to a certain point of time after harvest. In California, most citrus fruit are processed (presorted and packed) on the day of harvest. However, during the peak season, harvested fruit may be put aside unprocessed at the packinghouses until the next day owing to the high volume of harvested fruit to be processed. $B$. cinerea infects citrus fruit primarily through physical wounds on the fruit peel that are created at harvest or during postharvest handling. Thus, at the time of a postharvest fungicide treatment, wounds on the fruit may have already been contaminated by fungal spores. To control gray mold and other postharvest diseases initiated from wound infections, a timely application of postharvest treatments is important for achieving efficacy. In this study, natamycin efficacy was reduced when the treatment was delayed for $12 \mathrm{~h}$ or longer after inoculation, indicating that its curative activity may be limited. Our results suggested that, after harvest, immediate treatment with natamycin at citrus packinghouse would provide the best control of gray mold during storage.

Although an increase of disease incidence was observed on both natamycin-treated and fludioxonil-treated fruit as the storage time of inoculated fruit extended, it is likely that the efficacy of these fungicides was underestimated to some extent in this experiment, because in this study, the wound size on the fruit and artificial inoculation were used to mimic the worst case scenario of harvest and postharvest handling of mandarin fruit in which stem puncture wounds were created at harvest and the wounds were subsequently contaminated by the spores of $B$. cinerea. To help the citrus industry implement natamycin as a commercial postharvest treatment, commercial demonstration trials to treat naturally infected fruit with natamycin applied at various timings to simulate commercial postharvest handling scenarios would be beneficial. Nonetheless, this study documented the effectiveness of natamycin against $B$. cinerea strains resistant to other classes of fungicides.

Natamycin has been used for decades in the food industry, and no resistance has been reported in fungi (de Boer and Stolk-Horsthuis 1977; Oostendorp 1981). In a 2016 study, however, 13 of 19 fungal species showed increased MICs in a conidial germination assay after multiple transfers to media with increasing concentrations of natamycin (Streekstra et al. 2016). It is unknown whether repeated exposures of fungal spores to natamycin would result in increased MICs of natamycin for postharvest pathogens to a level that may compromise its control efficacy. This may be more important for Penicillium spp., because spores of Penicillium spp. are commonly present in citrus packinghouses and can be repeatedly exposed to the fungicide. Although the scope of this study is limited to $B$. cinerea, monitoring potential shifts of natamycin sensitivity in postharvest pathogens would be of importance to the citrus industry to maintain the efficacy of natamycin.

The efficacy of fungicides used to control certain citrus postharvest diseases may be improved when used in combination with salts or heat treatments. For instance, the addition of potassium sorbate or sodium bicarbonate to postharvest fungicides improved their performance to control green mold, blue mold, and sour rot during storage (Smilanick et al. 2006a, b, 2008) and could also reduce fungicide rates. Because salts or hot water treatments may be used during packing of citrus fruit, future studies should determine the compatibility of natamycin with common citrus postharvest treatments and evaluate the efficacy of these integrated approaches in controlling gray mold disease of stored mandarin fruit.

\section{Acknowledgments}

We thank K. Fjeld, K. Fisher, and D. Gautam for technical assistance and the citrus packinghouses for providing fruit samples. Mention of trade names or commercial products in this article is solely for the purpose of providing specific information and does not imply recommendations or endorsement by the U.S. Department of Agriculture (USDA). The USDA is an equal opportunity provider and employer.

\section{Literature Cited}

Al-Hatmi, A. M. S., Meletiadis, J., Curfs-Breuker, I., Bonifaz, A., Meis, J. F., and de Hoog, G. S. 2016. In vitro combinations of natamycin with voriconazole, itraconazole and micafungin against clinical Fusarium strains causing keratitis. J. Antimicrob. Chemother. 71:953-955.

Ando, N., and Takatori, K. 1987. Keratomycosis due to Alternaria alternata corneal transplant infection. Mycopathologia 100:17-22.

California Agricultural Statistics Service. 2004. 2004 California Citrus Acreage Report. Sacramento, California. https://www.nass.usda.gov/Statistics_by State/California/Publications/Specialty_and_Other_Releases/Citrus/Acreage/ 200412citac.pdf

California Agricultural Statistics Service. 2016. 2016 California Citrus Acreage Report. Sacramento, California. https://www.nass.usda.gov/Statistics_by_ State/California/Publications/Specialty_and_Other_Releases/Citrus/Acreage/ 201608citac.pdf

Cong, F., Zhang, Y., and Dong, W. 2007. Use of surface coating with natamycin to improve the storability of Hami melon at ambient temperature. Postharvest Biol. Technol. 46:71-75.

de Boer, E., and Stolk-Horsthuis, M. 1977. Sensitivity to natamycin (Pimaricin) of fungi isolated in cheese warehouses. J. Food Prot. 40:533-536.

Delves-Broughton, J., Thomas, L. V., Doan, C. H., and Davidson, P. M. 2005 Natamycin. Pages 275-289 in: Antimicrobials in Food, P. M. Davidson, J. N. Sofos, and A. L. Branen, eds. CRC Press, Boca Raton, FL.

Eckert, J. W., and Tsao, P. H. 1962. A selective antibiotic medium for isolation of Phytophthora and Pythium from plant roots. Phytopathology 52:771-777.

Fungicide Resistance Action Committee. 2018. FRAC Code List 2018. https:// www.frac.info/

Haack, E. S., Ivors, K. L., Holmes, G. J., Förster, H., and Adaskaveg, J. E. 2018. Natamycin, a new biofungicide for managing crown rot of strawberry caused by QoI-resistant Colletotrichum acutatum. Plant Dis. 102:1687-1695.

He, C., Zhang, Z., Li, B., Xu, Y., and Tian, S. 2019. Effect of natamycin on Botrytis cinerea and Penicillium expansum: Postharvest pathogens of grape berries and jujube fruit. Postharvest Biol. Technol. 151:134-141.

Holmes, G. J., and Eckert, J. W. 1999. Sensitivity of Penicillium digitatum and $P$. italicum to postharvest citrus fungicides in California. Phytopathology 89: 716-721.

Jurick II, W. M., Macarisin, O., Gakins, V. L., Park, E., Yu, J., Janisiewics, W., and Peter, K. A. 2017. Characterization of postharvest fungicide-resistant Botrytis cinerea isolates from commercially stored apple fruit. Phytopathology 107: 362-368.

Kanetis, L., Förster, H., and Adaskaveg, J. E. 2008. Baseline sensitivities for new postharvest fungicides against Penicillium spp. on citrus and multiple resistance evaluations in $P$. digitatum. Plant Dis. 92:301-310.

Leroux, L. 2004. Chemical control of Botrytis and its resistance to chemical fungicides. Pages 195-222 in: Botrytis: Biology, Pathology and Control, Y. Elad, B. Williamson, P. Tudzynski, and N. Delen, eds. Kluwer Academic Publishers, Dordrecht, The Netherlands.

McKay, A. H., Förster, H., and Adaskaveg, J. E. 2012. Efficacy and application strategies for propiconazole as a new postharvest fungicide for managing sour rot and green mold of citrus fruit. Plant Dis. 96:235-242.

Oostendorp, J. G. 1981. Natamycin. Antonie van Leeuwenhoek 47:170-171.

Saito, S., Michailides, T. J., and Xiao, C. L. 2016. Fungicide resistance profiling in Botrytis cinerea populations from blueberry in California and Washington and their impact on control of gray mold. Plant Dis. 100:2087-2093.

Saito, S., Michailides, T. J., and Xiao, C. L. 2019. Fungicide-resistant phenotypes in Botrytis cinerea populations and their impact on control of gray mold on stored table grapes in California. Eur. J. Plant Pathol. 154:203-213.

Saito, S., and Xiao, C. L. 2017. Prevalence of postharvest diseases of mandarin fruit in California. Plant Health Prog. 18:204-210.

Saito, S., and Xiao, C. L. 2018. Fungicide resistance in Botrytis cinerea populations in California and its influence on control of gray mold on stored mandarin fruit. Plant Dis. 102:2545-2549. 
Smilanick, J. L., and Mansour, M. F. 2007. Influence of temperature and humidity on survival of Penicillium digitatum and Geotrichum citri-aurantii. Plant Dis. 91:990-996.

Smilanick, J. L., Mansour, M. F., Gabler, F. M., and Goodwine, W. R. 2006a. The effectiveness of pyrimethanil to inhibit germination of Penicillium digitatum and to control citrus green mold after harvest. Postharvest Biol. Technol. 42: $75-85$.

Smilanick, J. L., Mansour, M. F., Gabler, F. M., and Soreson, D. 2008. Control of citrus postharvest green mold and sour rot by potassium sorbate combined with heat and fungicides. Postharvest Biol. Technol. 47:226-238.

Smilanick, J. L., Mansour, M. F., and Sorenson, D. 2006b. Pre- and postharvest treatments to control green mold of citrus fruit during ethylene degreening. Plant Dis. 90:89-96.

Smilanick, J. L., Michael, I. F., Mansour, M. F., Mackey, B. E., Margosan, D. A., Flores, D., and Weist, C. F. 1997. Improved control of green mold of citrus with imazalil in warm water compared with its use in wax. Plant Dis. 81:1299-1304.

Streekstra, H., Verkennis, A. E. E., Jacobs, R., Dekker, A., Stark, J., and Dijksterhuis, J. 2016. Fungal strains and the development of tolerance against natamycin. Int. J. Food Microbiol. 238:15-22.

te Welscher, Y. M., Jones, L., van Leeuwen, M. R., Dijksterhuis, J., de Kruijff, B., Eitzen, G., and Breukink, E. 2010. Natamycin inhibits vacuole fusion at the priming phase via a specific interaction with ergosterol. Antimicrob. Agents Chemother. 54:2618-2625.

te Welscher, Y. M., ten Napel, H. H., Balagué, M. M., Souza, C. M., Riezman, H., de Kruijff, B., and Breukink, E. 2008. Natamycin blocks fungal growth by binding specifically to ergosterol without permeabilizing the membrane. J. Biol. Chem. 283:6393-6401.

Tsao, P. H., and Ocano, G. 1969. Selective isolation of species of Phytophthora from natural soils on an improved antibiotic medium. Nature 223:636-638.

U.S. Environmental Protection Agency. 2012. Biopesticides Registration Action Document. Natamycin, PC Code: 051102. https://www3.epa.gov/ pesticides/chem_search/reg_actions/registration/decision_PC-051102_14May-12.pdf

U.S. Environmental Protection Agency. 2016. Master Label, Natamycin L. https:// www3.epa.gov/pesticides/chem_search/ppls/087485-00002-20160722.pdf

U.S. Department of Agriculture-National Agricultural Statistics Service. 2017 Citrus Fruits 2017 Summary. ISSN: 1948-9048. https://downloads.usda library.cornell.edu/usda-esmis/files/j9602060k/v979v5390/br86b605v/ CitrFrui-08-31-2017.pdf

van Leeuwen, M. R., Krijgsheld, P., Wyatt, T. T., Golovina, E. A., Menke, H., Dekker, A., Stark, J., Stam, H., Bleichrodt, R., Wösten, H. A. B., and Dijksterhuis, J. 2013. The effect of natamycin on the transcriptome of conidia of Aspergillus niger. Stud. Mycol. 74:71-85.

Webber, H. J., Barker, R., and Ferguson, L. 2014. History and development of the California citrus industry. Pages 3-20 in: Citrus Production Manual, Agriculture and Natural Resources Publication 3539, L. Ferguson and E. E. GraftonCardwell, eds. University of California, Oakland, CA.

Yigiter, B., Onay, F., Akgul, N. B., and Akocak, P. B. 2014. Natamycin treatment to control postharvest mold development and improve storability of citrus fruits J. Food Agric. Environ. 12:188-192. 